\title{
Rational imitation in preverbal infants
}

\section{Babies may opt for a simpler way to turn on a light after watching an adult do it.}

$\mathrm{H}^{2}$ ere we show that if an adult demonstrates a new way to execute a task to a group of infants aged 14 months, the children will use this action to achieve the same goal only if they consider it to be the most rational alternative. Our results indicate that imitation of goal-directed action by preverbal infants is a selective, interpretative process, rather than a simple re-enactment of the means used by a demonstrator, as was previously thought ${ }^{1-3}$.

In Meltzoff's seminal study ${ }^{1}$, a group of 14-month-old subjects watched a demonstrator illuminate a light-box by leaning forwards and touching its top with her forehead $^{1,2}$. One week later, two-thirds of them re-enacted this head action to achieve the same outcome, although none of the control group used it spontaneously. This was taken as evidence that infants separate the goal from the means, automatically imitating the means as demonstrated ${ }^{2}$. Such imitative learning is thought to be specific to humans, as primates do not imitate new strategies to achieve goals, relying instead on motor actions already in their repertoire (emulation $)^{3}$. If this were also the case in infants, they would be expected to touch the box with their hands, rather than imitating the unfamiliar head action. (Meltzoff, however, did not report such hand actions ${ }^{1,2}$.)

The readiness of infants to re-enact the head action is surprising, given that 1 -yearold babies can evaluate the rationality of the means in relation to the goal and the constraints of the situation ${ }^{4,5}$. When constraints change, these infants are able to work out the most effective action that the demonstrator should use to achieve the goal (the principle of rational action ${ }^{6,7}$ ). Infants would therefore be expected to re-enact an action only if it seemed to them to be the most effective means to achieve the goal (see also ref. 8).

So why did Meltzoff's subjects re-enact the head action, when they could just have touched the box with their hands? If infants noticed that the demonstrator declined to use her hands despite the fact that they were free, they may have inferred that the head action must offer some advantage in turning on the light. They therefore used the same action themselves in the same situation.

To test this idea, we replicated Meltzoff's study ${ }^{1}$ with one modification: in one condition, the subjects could see that the demonstrator's hands were occupied while she executed the head action (pretending to be cold, she had wrapped a blanket around herself which she held onto with both hands; 'hands occupied', Fig. 1a). After witnessing the same head action when the adult's hands
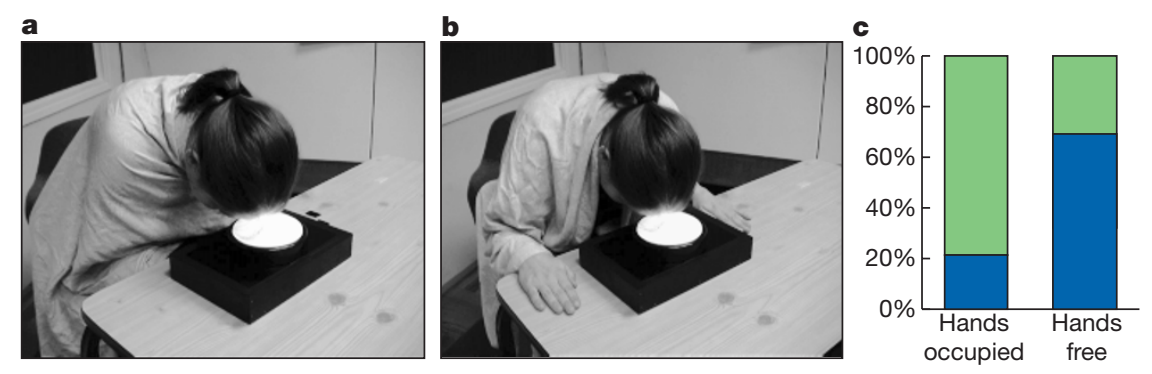

Figure 1 Comparison of the methods used by 14-month-old infants to switch on a light-box 1 week after watching how an adult executed the same task under two different conditions. $\mathbf{a}, \mathbf{b}$, Adult switching on the light by touching the lamp with her forehead in the hands-occupied condition (a, $n=14$ ) or the hands-free condition (b, $n=13$ ). c, Methods used by infants to switch on the light-box after watching the head action used by the demonstrator under these two conditions (left bar, adult had hands occupied; right bar, adult had hands free), recorded over a 20 -s period. Blue, head action was re-enacted; green, only manual touch was used. Further details are available from the authors. the head action, replicating Meltzoff's results ${ }^{1}$. However, after watching the adult turn on the light with her head when her hands were occupied, the number of children who imitated the head action dropped significantly to only $21 \%(P<0.02$; Fig. $1 c)$. It must therefore have seemed sensible to the infants that the demonstrator should use the head action when her hands were occupied - nevertheless, $79 \%$ of them chose not to imitate her because their own hands were free, presumably concluding that the head action was not the most rational.

Whether they re-enacted the head action or not, all infants who watched the adult perform under both conditions still used the hand action. This suggests that 14-monthold infants are still subject to an automatic, emulation-like process whereby the memory of the effect (illumination by touch) activates the response that is most strongly associated with establishing contact (hand action). But the re-enactment of the head action, when inferred to be rational by the were free (Fig. 1b), 69\% of infants re-enacted

infant, indicates that imitation by 14 month-olds goes beyond emulation. We conclude that the early imitation of goaldirected actions is a selective, inferential process that involves evaluation of the rationality of the means in relation to the constraints of the situation.

György Gergely, Harold Bekkering †‡, Ildikó Király*

${ }^{\star}$ Institute for Psychology, Hungarian Academy of Sciences, 1132 Budapest, Hungary

e-mail:gergelyg@mtapi.hu

$\dagger$ Max Planck Institute for Psychological Research, Amalienstrasse 33, 80799 Munich, Germany $\$$ Present address: Department of Experimental and Work Psychology, University of Groningen, 9712 TS Groningen, The Netherlands

1. Meltzoff, A. N. Dev. Psychol. 24, 470-476 (1988).

2. Meltzoff, A. N. J. Exp. Child Psychol. 59, 497-515 (1995).

3. Tomasello, M. The Cultural Origins of Human Cognition (Harvard Univ. Press, Cambridge, Massachusetts, 1999).

4. Gergely, G. et al. Cognition 56, 165-193 (1995).

5. Csibra, G. et al. Cognition 72, 237-267 (1999).

6. Gergely, G. \& Csibra, G. Cognition 63, 227-233 (1997)

7. Csibra, G. \& Gergely, G. Dev. Sci. 1, 255-259 (1998).

8. Bekkering, H., Wohlschlager, A. \& Gattis, M.

Q. J. Exp. Psychol. Human Exp. Psych. 53A, 153-164 (2000).

\section{Evolutionary biology}

\section{Performance constraints in decathletes}

hysical performance by vertebrates is thought to be constrained by tradeoffs between antagonistic pairs of ecologically relevant traits and between conflicting specialist and generalist phenotypes $^{1,2}$, but there is surprisingly little evidence to support this reasoning ${ }^{3-5}$. Here we analyse the performance of world-class athletes in standardized decathlon events and find that it is subject to both types of trade-off, after correction has been made for differences between athletes in general ability across all 10 events. These trade-offs may have imposed important constraints on the evolution of physical performance in humans and other vertebrates.

Decathletes compete in 10 different track and field events over two consecutive days. We constructed a data set of the performance of 600 world-class decathletes across all events from sources available on the Internet (see Fig. 1 legend). Individual performance for any pair of disciplines was positively correlated for the entire data set. This was unexpected, as physiological and biomechanical theory predicts that there should be trade-offs between certain pairs 


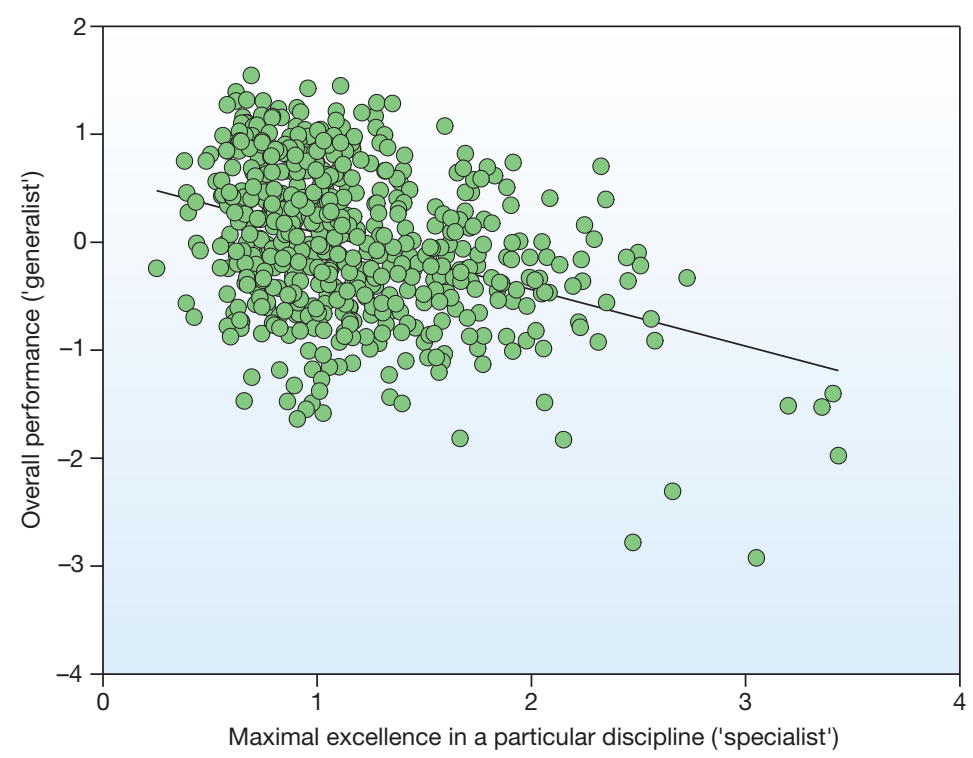

Figure 1 Trade-off between excellence in a single discipline (specialist) and average performance across all 10 events (generalist) for 600 world-class decathletes. Excellence in a particular discipline (represented by the highest residual score for a particular athlete) is negatively correlated with average performance (expressed as the average of all 10 residual scores for that athlete). To ensure that scores in different events received equal weighting, an athlete's score was standardized for each event by subtracting it from the population mean and dividing it by the population standard deviation. The decathlete data set was constructed from the following websites: www.iaaf.org; www.gbrathletics.com; www.athletics.org.au; www.dlv-sport.de; www.athle.org. of performance traits - for example, speed depends on the athlete having a high proportion of fast, fatigue-sensitive muscle fibres, whereas endurance relies on a higher proportion of slower fibres that are more resistant to fatigue ${ }^{3,6-8}$.

However, when the analysis was restricted to athletes of comparable ranking (on the basis of International Amateur Athletic Federation scores), trade-offs became evident between certain traits. For example, performance in the 100 metres is negatively correlated with speed over 1,500 metres for athletes who score above 8,000 points $(n=133 ; r=-0.21, P=0.016)$. We suspect that the apparent contradiction in our results is caused by differences in 'general quality' between athletes, which effectively mask any trade-off effects when the entire population is examined.

To account for these differences in general quality, we calculated partial correla-

tion coefficients for each pair of performance traits and found evidence of some performance trade-offs (Table 1). For example, good sprinters performed relatively poorly over 1,500 metres, but did well in the long jump, the 400 metres and the 110-metre hurdles. Likewise, there was a negative correlation between performance in shot-putting (which calls for explosive power in the upper limbs) and in the 1,500 metres (which depends on endurance in the lower limbs).

These results seem to support the idea of trade-offs generated by conflicting anatomical (such as relative body weight and limb proportions) and muscle-fibre-type requirements. Negative correlations may also reflect differences in training, for example if athletes focus on certain disciplines to the detriment of others. However, the consistency with which particular performance traits co-vary suggests that it

\begin{tabular}{|c|c|c|c|c|c|c|c|c|c|}
\hline & Shot putt & Javelin & Pole vault & High jump & Long jump & $100 \mathrm{~m}$ & 110-m hurdles & $400 \mathrm{~m}$ & $1,500 \mathrm{~m}$ \\
\hline Discus & + & + & NS & NS & NS & NS & NS & NS & NS \\
\hline Shot putt & & + & NS & NS & NS & NS & NS & NS & - \\
\hline Javelin & & & NS & NS & NS & NS & NS & NS & NS \\
\hline Pole vault & & & & + & NS & NS & + & NS & NS \\
\hline High jump & & & & & + & NS & + & NS & NS \\
\hline Long jump & & & & & & + & + & $\mathrm{NS}$ & NS \\
\hline $100 \mathrm{~m}$ & & & & & & & + & + & - \\
\hline 110-m hurdles & & & & & & & & + & NS \\
\hline $400 \mathrm{~m}$ & & & & & & & & & + \\
\hline
\end{tabular}

Decathlon competitions consist of: first day, 100 metres, long jump, shot putt, high jump and 400 metres; second day, 110-metre hurdles, discus, pole vault, javelin and 1,500 metres. Partial correlation coefficients were used to adjust correlations between performance pairs for an athlete's overall ability on the basis of the other events (regardless of physiological similarity between traits). For each decathlete, all performance results are taken from their best decathlon score. All data (units in $\mathrm{m}$ or in $\mathrm{m} \mathrm{s}^{-1}$ ) were log-transformed. Significant positive $(+)$ and negative $(-)$ correlations $(P<0.0001)$ were intact after Bonferroni correction (d.f., 590); NS, not significant. is more difficult to combine excellence in some pairs of events than in others.

We calculated measures of excellence and average performance for each decathlete across all disciplines to test the assumption that there must be a performance trade-off between specialist and generalist phenotypes. The principle of allocation, a hypothesis that underlies much of ecological and evolutionary theory, predicts that excellence in one task can only be attained at the expense of average performance in all other tasks, and vice versa ${ }^{1}$.

For each athlete, we selected the highest standardized score from his set of 10 events and defined this as that athlete's 'degree of excellence'. We also calculated the average of the 10 scores for each athlete to estimate their overall average performance. The degree of excellence was negatively correlated with average performance across all disciplines ( $r=-0.37, P<0.00001$; Fig. 1 ), which is consistent with the principle of allocation.

We conclude that in an environment in which the selection criterion is combined high performance across multiple tasks, increased performance in one function may impede performance in others. The relevance of our findings for the evolution of performance traits will depend on whether these correlations have a genetic basis studies of mice ${ }^{9}$ and insects ${ }^{10}$ indicate that this may be the case. The influence of an individual athlete's training schedule or career development on these apparent trade-offs also needs to be determined.

Raoul Van Damme, Robbie S. Wilson, Bieke Vanhooydonck, Peter Aerts

Department of Biology, University of Antwerp,

Universiteitsplein 1, 2610 Wilrijk, Belgium

e-mail:rwilson@uia.ac.be

1. Levins, R. Evolution in Changing Environments (Princeton Univ. Press, New Jersey, 1968).

2. Futuyma, D. J. \& Moreno, G. Annu. Rev. Ecol. Syst. 19, 207-233 (1988).

3. Garland, T. Jr in Quantitative Genetic Studies of Behavioral Evolution (ed. Boake, C. R. B.) 251-277 (Univ. Chicago Press, Chicago, 1994)

4. McPeek, M. A. Am. Nat. 148 (suppl.), 124-138 (1996).

5. Whitlock, M. C. Am. Nat. 148 (suppl.), 65-77 (1996).

6. Vanhooydonck, B., Van Damme, R. \& Aerts, P. Evolution 55, 1040-1048 (2001).

7. Esbiörnsson, M., Sylvén, C., Holm, I. \& Jansson, E. Int. J. Sports Med. 14, 257-263 (1993).

8. Rivero, J. L., Serrano, A. L., Henckel, P. \& Agüera, E. J. Appl. Physiol. 75, 1758-1766 (1993).

9. Dohm, M. R., Hayes, J. P. \& Garland, T. Jr Evolution 50, 1688-1701 (1996).

10. Gilchrist, G. W. Evolution 50, 1560-1572 (1996).

Competing financial interests: declared none.

brief communications is intended to provide a forum for brief, topical reports of general scientific interest and for technical discussion of recently published material of particular interest to non-specialist readers. Priority will be given to contributions that have fewer than 500 words, 10 references and only one figure. Detailed guidelines are available on Nature's website (www.nature.com) or on request from nature@nature.com 